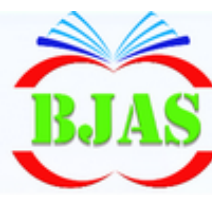

ISSN 1814 - 5868
Available online at http://bajas.edu.iq

https://doi.org/10.37077/25200860.2019.282

College of Agriculture, University of Basrah

Basrah J. Agric. Sci., 32(Spec. Issue 2), 352-359, 2019
Basrah Journal

of Agricultural

Sciences

E-ISSN: 2520-0860

\title{
The Efficiency of the Parasitoids Bracon hebetor and B. brevicornis in the Control of Date Palm Moth Cadra cautella (Lepidoptera: Pyralidae)
}

\author{
Raja M. Khalaf \& Ayad A. Abdulkader \\ Department of Plant Protection, College of Agriculture, University of Basrah, Iraq \\ *Corresponding author e-mail:rajamalik280@gmail.com
}

Received 2 March 2019; Accepted 9 December 2019; Available online 22 December 2019

\begin{abstract}
The current research was carried out to study the parasitism efficiency of the parasitoids Bracon hebetor and Bracon brevicornis in the control of Cadra cautella. Under the lab condition. The results showed that the treatment of four pairs of Bracon hebetor. 10 larvae $^{-1}$ of the date moth gave the highest number of deposited eggs. The results showed that the treatment of four pairs of Bracon brevicornis. 10 larvae $^{-1}$ of the date moths gave the highest number of parasitized larvae, the number of deposited eggs, the number of emerged adults and the percentage of parasitism. The treatment of a pair of parasitoid. 10 larvae decreased the number of parasitized larvae, deposited eggs, emerged adults and the parasitism rate, while these treatments cause the highest number of paralyzed larvae, reaching 9 larvae. In the warehouse experiment, the results of treatments of 20,30 and 40 pairs of released B. hebetor in the date's warehouse showed a significant difference after five days of treatment. The treatment of 40 pairs reported the highest number of parasitized larvae, the number of deposited eggs and the number of emerged adults and the percentage of parasitism, compared to the treatment of 20 pairs which caused the lowest numbers and rates.
\end{abstract}

Keywords: Cadra cautella, Bracon hebetor, Bracon brevicornis

\section{Introduction}

Date palms (Phoenix dactylifera L.) belonging to the family Aracaceae are the most important fruit trees in Iraq. The stored dates infested by different species of moths including the genus Cadra moth belonging to the Pyralidae family. The date moth Cadra cautella Walker is the most destructive date pests among Pyralid moths, in subtropical and equatorial regions (Horak, 1999). C. cautella was first recorded in Iraq by Burges (1965), Saray (2010), and Tarek et al. (2014). Date Palm moth is nocturnal, spending its life cycle in the dark places of stores (Sharma et al., 2007). The larva causes serious damage for the fruits and provides a suitable environment for the growth of bacteria and fungi; the total production losses ranged 5-50\% (Muhsin, 2001; Al-Zadjali et al., 2006; Abdulrahman et al., 2013).

Date Palm Moth is attacked by the parasitoid B. hebetor and B. brevicornis (Hymenoptera, Braconidae) which has been successfully used in biocontrol programs. $B$. 
Khalaf \& Abdulkader / Basrah J. Agric. Sci., 32(Spec Issue 2): 352-359, 2019

hebetor is highly specialized on Lepidoptera larvae; the parasitoid is an active, highly productive and adaptive ability to various natural environmental conditions and the ease of breeding and propagation (Mohsen, 2001).

The aim of the study is to evaluate the Efficiency of the Parasitoids B. hebetor and $B$. brevicornis in the control of $C$. cautella.

\section{Materials \& Methods}

\section{Collection of samples}

Infested date palms stores were sampled in Shatt al-Arab, Faw, Zubayr, Abu Al-Khaseeb, Qurna and Kerma Ali in Basrah province. In order to diagnose the insect, the infested fruits were collected and brought to the laboratory of Department of Plant Protection, College of Agriculture, University of Basrah for further studies.

The samples were sent to the Museum of Natural History in Baghdad. The diagnosis was done by Prof. Dr. Saleh Abdul Rasoul and confirmed the change of scientific name due to the genus change from Ephestia to Cadra for special taxonomic considerations.

\section{Rearing of $C$. cautella}

Al-Khadrawi, Al-Barim, Al-Sayer and AlHalawi date palm cultivars were selected for rearing the insect in the Department of Plant Protection laboratory. The selection of these varieties was due to the preference and availability in the province of Basrah. Five hundred grams of date were weighed by a sensitive balance for each type, 3 replicates and 7 different areas in Basrah. They were placed in plastic containers $15 \mathrm{~cm}$ long and 12 $\mathrm{cm}$ in diameter which were covered with fine mesh cloth which prevented leaving the larvae after being installed in the laboratory conditions.

\section{Rearing of B. hebetor and B. brevicornis}

Different stages of the parasitoid B. hebetor were brought form department of Plant Protection, University of Baghdad. The parasitoid B. brevicornis was collected in late March from warehouses at different regions. Samples were putting in test tubes $(30 \mathrm{~cm}$ in length and $2.5 \mathrm{~cm}$ in diameter) containing larvae, pupae and adults of the parasitoid; these test tubes were blocked by a cotton wet with a $10 \%$ glycoprotein solution so that adults fed on them., then the male and female parasitoids were transferred to plastic boxes $(30 \mathrm{~cm} \times 2.5 \mathrm{~cm})$ including the fourth and fifth larvae of date moths larvae. Each box was provided with a piece of cotton moistened with a $10 \%$ sugar solution for the feeding. Three pairs of parasitoids were placed in each pack and six larvae were added from the fourth and fifth stage moths. The boxes were placed in the incubator at $30^{\circ} \mathrm{C}$ and $42 \%$ R.H and light 12 hours.

The larvae that remained in the test tubes were transferred to $9 \mathrm{~cm}$ diameter Petri dishes. The dishes were then covered with an orange cloth and sealed with a rubber band. The dishes were kept in the incubator at $30{ }^{\circ} \mathrm{C}$ and $42 \%$ R.H and light 12 hours.

For the parasitoid pupa that was attached to the internal walls of the test tube, the incubator was also kept at $30{ }^{\circ} \mathrm{C}$ and $42 \%$ R.H, monitored until the adult emerged from the cocoons (Ramahi \& Ali, 1983).

\section{Bracon hebetor and $B$. brevicornis parasitism efficacy test in the lab}

The parasitism efficacy of the parasitoid, $B$. hebetor on the date moth was calculated in the laboratory conditions. About 1, 2, 3 and 4 pairs of parasitoid were placed in new plastic boxes (length $7 \mathrm{~cm}$ and width $4 \mathrm{~cm}$ ) containing 10 larvae of the fourth and fifth 
instars after collecting from the infested fruits of date palm. The boxes were provided with a drop of honey on the cotton to feed the parasitoid. The containers were kept at $30{ }^{\circ} \mathrm{C}$ and $42 \%$ R.H.

The larvae were isolated, then the number of the un-parasitized larvae, parasitized larvae (larvae on which the eggs were laid), and the paralyzed larvae were recorded separately. The number of eggs of parasitoids and the number of pupae emerging from the cocoons was also recorded (Al-Ramahi \& Ali, 1983).

\section{Bracon hebetor parasitism efficacy test in the warehouses}

A date warehouse was selected in one of the orchards of the Shatt al-Arab / Bab Daij region, in Basrah province; the warehouse (5.5 $\mathrm{m}$ long and $3.5 \mathrm{~m}$ wide and $3.5 \mathrm{~m}$ high) was made of bricks and covered with metal. Three plastic boxes $(15 \mathrm{~cm}$ long and $12 \mathrm{~cm}$ in diameter) were taken. 25 larvae (the third and fourth phase moths) were placed in a box including $50 \mathrm{~g}$ of dates. Each box was covered with the fine mesh cloth and fastened with a rubber band that did not allow the larvae to leave and in the same time allowed the parasitoid to enter; the boxes were placed on a table at a height of one meter in one side of the store. The larvae were examined for their parasitism efficiency. The number of larvae on which the eggs were laid, the number of eggs, the number of pupae and the percentage of parasitism were calculated. The same experiment was repeated on other boxes were 40 and 30 pairs of parasitoids were released separately. The experiment was conducted at $28 \pm 2{ }^{\circ} \mathrm{C}$ and humidity of $40 \pm$ $3 \%$ (Shawkit et al., 2014). Laboratory and laboratory experiments were carried out according to the complete random design (C.R.D) and the averages were compared to L.S.D (Al-Rawi, 1980).

\section{Results \& Discussion}

\section{The parasitism efficacy of $B$. hebetor parasitoid on the $C$. cautella}

The results of table (1) showed that there was no significant difference observed for the effect of the $B$. hebetor parasitoids release density on the number of paralyzed followed by treatment of two pairs of parasitoid. $10^{-1}$ larvae with average of 8.3 larvae; however, the lowest number of paralyzed larvae was 6.3 in the treatment of four pairs.10 larvae $^{-1}$. Also, the results showed that the mean total numbers of eggs laid by $B$. hebetor females varied; the treatment of four pairs of parasitoid. 10 larvae $^{-1}$ gave the highest number of eggs, with average of 22 eggs and there was no significant difference from the treatment of three pairs of parasitoid. 10 larvae $^{-1}$, reaching 18.6 eggs, whereas the lowest number of eggs were 7.3 eggs/ one pair of parasitoid/ 10 larvae.

The results of the statistical analysis showed a significant difference in number of adults emerged at the four densities released parasitoid at 10 larvae of date moth; the highest number of adult emerged were 19 at density of four pairs of parasitoid.10 larvae $^{-1}$, without a significant difference, followed by the treatment of three pairs.10 larvae $^{-1}$, reaching 17.6 adults, While the lowest number was 6.6 adults/ one pair of parasitoid. 10 larvae $^{-1}$.

Parasitism of larvae by $B$. hebetor has been significantly affected by the density of parasitoids; the highest Parasitism percent was $36.6 \%$ in the treatment of four pairs of parasitoid.10 larvae $^{-1}$ of the date moth, whereas the lowest percentage was $10 \%$ in the treatment of one pair parasitoids. 10 larvae $^{-1}$.

The results of this study showed that the number of deposited eggs increased as the 
number of released pairs of parasitoids increased. The study also indicated that the parasitoids preferred to select the fifth stage of the larvae, which is larger than the fourth stage for Eggs depositing. The results showed that although the parasitoid paralyzed a large number of host larvae, it deposited all the eggs on one host larva, thus all parasitoid larvae live on the same host and complete all larval stages without any competition for food. The results were in agreement with of Al-Ramahi \& Ali (1983) that reported that the parasitoid preferred the fourth and fifth stages for egg deposition due to the availability of nutrition for the newly hatched larvae (Gupta, 2013).

Table. (1) Parasitism efficacy of parasitoid Bracon hebetor on the date moth Cadra cautella in the lab.

\begin{tabular}{cccccc}
\hline Treatment & $\begin{array}{c}\text { No. paralyzed } \\
\text { larvae }\end{array}$ & $\begin{array}{c}\text { No. } \\
\text { parasitized } \\
\text { larvae }\end{array}$ & $\begin{array}{c}\text { No. eggs } \\
\text { deposited on } \\
\text { the host }\end{array}$ & $\begin{array}{c}\text { No. emerged } \\
\text { adults }\end{array}$ & Parasitism \% \\
\hline $\begin{array}{c}\text { One pair of } \\
\text { parasitoid.10 } \\
\text { larvae }\end{array}$ & 9 & 1 & 7.3 & 6.6 & 10 \\
\hline $\begin{array}{c}\text { two pair of } \\
\text { parasitoid.10 } \\
\text { larvae }\end{array}$ & 8.3 & 1.6 & 13.6 & 12 & 16.6 \\
\hline $\begin{array}{c}\text { three pair of } \\
\text { parasitoid. 10 } \\
\text { larvae }\end{array}$ & 7 & 3 & 18.6 & 17.6 & 30 \\
\hline $\begin{array}{c}\text { four pair of } \\
\text { parasitoid. 10 } \\
\text { larvae }\end{array}$ & 6.3 & 3.6 & 22 & 19 & 36.6 \\
\hline
\end{tabular}

LSD $(0.05)=$ Number of parasitized larvae $=0.88 ;$ Number of paralyzed larvae $=0.87$ number of deposited eggs $=4.21$; number of emerged adults $=3.663$ parasite percentage $=8.81$

The parasitism efficacy of the parasitoid $B$. brevicornis on $C$. cautella larvae in the laboratory

The results of table (2) showed that there was no significant difference among the released densities of $B$. brevicornis on the number of parasitized larvae; the highest number of parasitized larvae of the date moth was 3.33 larvae at the released parasitoid density of 4 pairs.10 larvae $^{-1}$ of the date moth. The results showed a significant difference among the released densities of $B$. brevicornis on the number of paralyzed larvae with the highest value in the number of larvae paralyzed 9.00 in the treatment of one pair of parasitoid and the lowest value of 6.6 in the treatment of four pairs of parasitoid.10 $\operatorname{larvae}^{-1}$ of the date moth.

The highest eggs deposited was 13.67 at the treatment of four pairs. 10 larvae $^{-1}$ of the date moth, and the lowest treatment reached 5.00 eggs. 1 pair ${ }^{-1} .10$ larvae $^{-1}$. There was no significant difference between the treatment of four pairs and the three pairs of parasitoids. 10 larvae $^{-1}$ of the date moth.

The results of the statistical analysis showed a significant difference of the effectiveness of the released parasitoid densities on emerged adults, the highest number of emerged adults was 10.67 at the treatment four pairs of parasitoids. 10 larvae $^{-1}$ from the date moth and the lowest value was 
4.00 in the density of one pair and three pairs of parasitoids.10 larvae $^{-1}$ of the date moth. Regarding the parasitism percentage. The highest percentage was $33.3 \%$ in the treatment of four pairs.10 larvae $\mathrm{e}^{-1}$ and $10 \%$ in the one pair of parasitoids treatment. The results revealed that the higher the number of released pairs of parasitoids, the higher the parasitism rates; thus reducing the number of date moths in infested date`s stores.

The results showed that B. brevicornis has high ability to parasitize the larvae of the date moths and because of the paralysis of all larvae in the breeding tubes and the high number of eggs deposited by one female, parasitism efficiency was increased. These results were in agreement with Al-Abdullah (2009) who explained that the high capacity of the parasitoids to withstand the high temperature, for that the weather of province of Basrah increases the successful chance of using the parasitoids in the programs of biological control of date moths in the stores. Whereas the parasitoids $B$. hebetor cannot withstand high temperatures despite its high parasitism efficiency.

Fig. (2): The parasitism efficacy of the parasite Bracon brevicornis on the dates moth Cadra cautella in lab.

\begin{tabular}{cccccc}
\hline Treatment & $\begin{array}{c}\text { No. paralyzed } \\
\text { larvae }\end{array}$ & $\begin{array}{c}\text { No. } \\
\text { parasitized } \\
\text { larvae }\end{array}$ & $\begin{array}{c}\text { No. eggs } \\
\text { deposited on } \\
\text { the host }\end{array}$ & $\begin{array}{c}\text { No. emerged } \\
\text { adults }\end{array}$ & Parasitism \% \\
\hline $\begin{array}{c}\text { One pair of } \\
\text { parasitoid.10 } \\
\text { larvae }\end{array}$ & 9 & 1 & 5 & 14 & 10 \\
\hline $\begin{array}{c}\text { two pair of } \\
\text { parasitoid.10 } \\
\text { larvae }\end{array}$ & 8.3 & 1.6 & 6.6 & 5.6 & 16.6 \\
\hline $\begin{array}{c}\text { three pair of } \\
\text { parasitoid.10 } \\
\text { larvae }\end{array}$ & 7.3 & 2.6 & 11 & 10.3 & 26.6 \\
\hline $\begin{array}{c}\text { four pair of } \\
\text { parasitoid.10 } \\
\text { larvae }\end{array}$ & 6.6 & 3.3 & 13.6 & 10.6 & 33.3 \\
\hline
\end{tabular}

$\operatorname{LSD}(0.05)=$ Number of parasitized larvae $=0.94 ;$ Number of paralyzed larvae $=0.99$ number of deposited eggs $=3.37$; number of emerged adults $=2.10$ parasite percentage $=0.09$

Comparison between the efficiency of the Bracon hebetor parasite and the efficiency of the Bracon brevicornis parasitoids on the date moth larvae

The results of table (3) showed a significant difference between parasitoids in the number of eggs deposited by one female on 10 larvae of the date moth as well as the number of adults emerged of parasitoid $B$. hebetor with average of 7.5 eggs and 6.6 emerged adults respectively, compared to $B$. brevicornis (5 eggs and 4 emerged adults). Al-Remahi and
Ali (1983) reported that the number of eggs laid by a female of $B$. hebetor. 10 larvae $^{-1}$ of the date moth reached 19 eggs during two days at a temperature of $26{ }^{\circ} \mathrm{C}$ and humidity of $60 \%$.

The efficiency of $B$. hebetor parasitoid on the date moth $C$. cautella in the date's warehouse

The parasitism efficiency of $B$. hebetor on the larva of date moth $C$. cautella in the store after 5 days of releasing showed a significant difference in the treatment (Table 4). 
Khalaf \& Abdulkader / Basrah J. Agric. Sci., 32(Spec Issue 2): 352-359, 2019

Table (3): Comparison of the parasitism efficacy of the Bracon hebetor and Bracon brevicornis on the date moth larvae in the laboratory.

\begin{tabular}{|c|c|c|c|c|}
\hline Parasitoid & $\begin{array}{l}\text { No. emerged } \\
\text { adults }\end{array}$ & $\begin{array}{lr}\text { No. deposited } \\
\text { eggs/ } \\
\text { female. } \\
\text { larvae }^{-1}\end{array}$ & $\begin{array}{l}\text { No. } \\
\text { paralyzed } \\
\text { larvae }\end{array}$ & $\begin{array}{l}\text { No. } \\
\text { parasitized } \\
\text { larvae }\end{array}$ \\
\hline Bracon hebetor & 6.6 & 7.5 & 9 & 1 \\
\hline Bracon brevicornis & 4 & 5 & 9 & 1 \\
\hline
\end{tabular}

LSD $(0.05)=$ Number of parasitized larvae $=0.0$; Number of paralyzed larvae $=0.0$ number of deposited eggs $/$ female $=1.434$; number of emerged adults $=3.795$

When 40 pairs of parasitoids were applied, the highest number of parasitized larvae, the highest number of Deposited eggs on the larva, the highest number of emerged adults and the percentage of parasitism were recorded and reached 18.3 larvae, 78.7 eggs, 67.8 adults and $73.2 \%$, respectively. Followed by, 30 pairs of parasitoids resulted in 6.8 parasitized larvae, 39.8 eggs, 35.6 adults and $27.2 \%$. While the total of 4.3 larvae, 27.2 eggs, 23.8 adults and $17.2 \%$ was recorded at 20 pairs of parasitoids. The highest number of paralyzed larvae was 19.3 at treatment of 20 pairs, followed by 15 paralyzed larvae. 30 pairs $^{-1}$, whereas the lowest of paralyzed larvae 4.2 larvae at the treatment 40 pairs.

Table (4): The parasitism efficacy of the Bracon hebetor parasitoid on the dates moth larvae in the date`s warehouse.

\begin{tabular}{cccccc}
\hline Treatments & $\begin{array}{c}\text { No. } \\
\text { parasitized } \\
\text { larvae }\end{array}$ & $\begin{array}{c}\text { No. } \\
\text { paralyzed } \\
\text { larvae }\end{array}$ & $\begin{array}{c}\text { No. eggs } \\
\text { deposited on } \\
\text { the larvae }\end{array}$ & $\begin{array}{c}\text { No. } \\
\text { emerged } \\
\text { adults }\end{array}$ & Parasitism \% \\
\hline $\begin{array}{c}\text { 20 pairs of } \\
\text { parasitoid }\end{array}$ & 4.3 & 19.3 & 27.2 & 23.8 & 17.2 \\
\hline $\begin{array}{l}\text { 30 pairs of } \\
\text { parasitoid }\end{array}$ & 6.8 & 15.0 & 39.8 & 35.6 & 27.2 \\
\hline $\begin{array}{l}\text { 40 pairs of } \\
\text { parasitoid }\end{array}$ & 18.3 & 4.2 & 78.7 & 67.8 & 73.2 \\
\hline
\end{tabular}

LSD $(0.05)$ the number of parasitized larvae $=5.24$; LSD $(0.05)$ the number of paralyzed larvae $=2.88 ;$ LSD $(0.05)$ the number of eggs deposited $=10.97$; LSD $(0.05)$ the number of emerged adults of parasitoids $=7.331 ;$ LSD $(0.05)$ parasitism $\%=9.72$

An increasing number of parasitized larvae the eggs deposited on the larvae, the number of emerged adults and the percentage of parasitism in the treatment 40 pairs of parasitoid were related to increased numbers of parasitoids compared to other treatments, thus the more pairs of parasitoids, the greater the chances of mating and increasing the parasitism. The results are in agreement with
Shawkit et al. (2014) that proving the parasitism efficacy of the parasitoids and the high ability to research for the host.

\section{Conclusions}

The results revealed to the high parasitism efficacy of $B$. hebetor on the date moths of $C$. cautella compared to parasitoid $B$. brevicornis. The highest temperature a 
Bracon hebeto can withstand to perform the biological function was $34{ }^{\circ} \mathrm{C}$, while Bracon brevicornis can withstand high temperatures up to $40^{\circ} \mathrm{C}$.

\section{Acknowledgements}

We would like to thank staff and faculty of Department of Plant Protection, College of Agriculture, and University of Basrah for help the authors during the research, and Prof. Dr. Asaad Y. Ayied, from Department of Animal Production for Statistical Analysis; finally many thanks for Prof. Dhia K. Kareem, from College of Education and Pure Sciences for identifying the insects.

\section{References}

Adams, J.M. (1976). A guide to the objective and reliable estimation of food losses in small scale farmer storage. Tropical stored Products Information, 32: 5-12.

Abdulrahman, S.H.; Khawaja, G.R.; Abdullah, A.S.; Mureed, K.D. \& Mahammad, T. (2013). Effects of tempertuer on the development of Ephestia cautella (walker) (Pyralidae: Lepidoptera) a case study for its possible control under storage conditions. Pakistan J. Zool., 45(6): 1573-1576.

Al-Abdullah, B.; Al-Hamada, J.; Celtie, M.N. \& Aslan, L. (2001). The effect of host and temperatures on some biological processes efficiency of larval parasite Bracon brevicornis (Hymenoptera: Braconidae) under laboratory conditions. Damascus Univ. J. Agric. Sci., 25(1): 345-365.

Al-Ramahi, R.S. \& Ali, M.H. (1983). Effect of diets on the longevity of the adult parasitoid Bracon hebetor Say. Yearbook Plant Pro. Res., 3(1): 29-38.

Al-Rawi, Kh.M. \& Khalfalla, A.M. (1980). Design and analysis of agricultural experiments. Directorate of residence House Print. Publ., Univ. Mosul: 488pp. (In Arabic).

Al-Zadjali, T.S.; Abdallal, F.F. \& El-Haidari, H.S. (2006). Insect pests attacking date palms and dates in Sultanate of Oman. Egypt. J. Agric. Res., 84: 51-59.

Horak, M. (1994). A review of Cadra walker in Australia: five new native species and the tow introduced pest species (Lepidoptera: Pyralidae: Phycitinae). Aust. J. Entomol., 33(3): 245-262.

Gupta, A. \& Lokhande, S.A. (2013). A new host record and a new combination in Cotesia cameron (Hymenoptera: Braconidae) from India. J. Threatened Taxa, 5(2): 3678-3681.

Mohsen, A.A. (2001). Control of Ephestia cautella: Lepidoptera: Pyralidae using parasitoid Bracon hebetor Say (Hymenoptera: Braconidae) gamma ray. M. Sc. Thesis, Coll. Educ. Women, Univ. Baghdad: 96pp. (In Arabic).

Saray, M.H. (2010). Effect of laser in some aspects of the life performance of the insect mite Ephestia cautella: Lepidoptera: Pyralidae. Biotechnol. Res. Cent. Coll. Sci. Univ. Baghdad, 4(2): 62-66.

Tarek, M.A.; Mohamed, H.A. \& Al-Jalely, B.H. (2014). Bioprotective evaluation of Beauveria bassiana (Bals.) Vuill on the different stages of fig moth Ephestia cautella: (Lepidoptera: Pyralidae) in vitro. J. Kerbala Univ., 12(1): 190-196. (In Arabic).

Sharma, H.C.; Ashok-Aluv, S.; RavinderReddy, C.H.; Jayaraj, K.; Varaprasad, V.J.; Varaprasad-Reddy, K.M.; Belum, V.S. \& Reddy-Rai, K.N. (2007). Management of sorghum and pearl millet pestin Bulk storage. Global theme on crop 
Khalaf \& Abdulkader / Basrah J. Agric. Sci., 32(Spec Issue 2): 352-359, 2019

Improvement. International crops Research Institute for the Arid Tropics. Patan Cheru 502-324, Andra Pradesh, India: 20pp.

Shawkit, M.A.; Hamad, B.S.; MassehKhder, N.A.; Hamed, A.A. \& Al-Tweel, A.A.
(2014). Searching capacity of Habrobracon hebetor Say (Hymenopetra: Braconidae) for its host larvae in simulated date store. J. Madenat Alelem Univ. Coll., 6(1): 30-38. 